\title{
KEHAKIMAN DAN PENGHAKIMAN MAHKAMAH SYARIAH DI MALAYSIA: SATU SOROTAN
}

\section{Judiciary and Judicial Decision of the Shariah Courts in Malaysia: A Literature Review}

\author{
Zulzaidi Mahmod \\ Ph.D Candidate, Department of Shariah and Law, \\ Academy of Islamic Studies, \\ University of Malaya, 50603 Kuala Lumpur. \\ zulzaidi86@gmail.com \\ Ahmad Hidayat Buang \\ Professor, Department of Shariah and Law, \\ Academy of Islamic Studies, \\ University of Malaya, 50603 Kuala Lumpur. \\ ahidayat@um.edu.my
}

\begin{abstract}
Orders and judgments in Shariah Courts have often being challenged at a higher level. Not only that the laws applied in Shariah Court itself also have been challenged in the Civil Courts. As many studies have made in the past on this issues, this article aims to review the related literatures on the subject. Through content analysis of the literatures it found that most of the studies concentrated on organization, function and jurisdiction of the judicial institutions of Shariah Court in Malaysia. Only a little number of the studies analyzed the reasons that led to the grounds of judgment and methods and principles used in the court decision. Based on literature point of view, it can be observed that the judges in Shariah Court have lack of understanding towards the importance and role of judgment methodology in order to come up with a just and transparent decision so much so their grounds of judgment are sometimes be impractical and refutable.
\end{abstract}

Keywords: Shariah Court, Islamic Judiciary, judgment, grounds of judgment

* Data-data dalam artikel ini diambil daripada Projek FP030-2016 Universiti Malaya. 


\section{PENDAHULUAN}

Institusi kehakiman merupakan sebuah institusi yang menjalankan tugas keadilan untuk memberi hak kepada yang berhak (Sharaf al-Dīn, 1996: 11) dan berhukum di antara manusia (Ibn Qudāmah, 2004: 2507) dalam menyelesaikan perkara di antara orang yang dizalimi dan orang zalim (Muhammad al-Zuhaylī, 2011: 372). Bidang kehakiman merupakan tugas yang mulia dan pegawai yang terlibat dalam bidang ini memikul tanggungjawab yang sangat berat (Syed Agil Barakbah, 2000: 83).

Sesebuah institusi kehakiman Islam memerlukan kepada beberapa elemen utama seperti mahkamah, Hakim Syarie, pegawai mahkamah, pendaftar mahkamah, bailif, Peguam Syarie, Pendakwa Syarie dan sebagainya. Kesemuanya adalah bergantung antara satu sama lain untuk memastikan tugas memberi keadilan adalah berjalan dengan baik dan sempurna. Walaubagaimanapun perkara paling penting dalam institusi kehakiman adalah kredibiliti sesorang hakim dalam membuat keputusan dan penghakiman serta alasan penghakiman.

\section{SOROTAN KAJIAN LEPAS}

Penyelidik telah menggunakan beberapa tesis, disertasi, artikel jurnal dan buku untuk menyorot berkenaan tajuk yang dibuat (Sabitha Marican, 2005: 261), iaitu berkenaan dengan kaitan penghakiman di Mahkamah Syariah. Sorotan kajian ini adalah melihat kepada kajian-kajian lepas (Akademi Pengajian Islam, t.t.: 15), untuk meneliti secara dasar kepada kajian terdahulu dalam merangka kajian penyelidik secara tepat tanpa ada sebarang pertindihan kajian yang dilakukan. Secara umumnya telah terdapat banyak penulisan dan kajian yang melibatkan berkenaan dengan Mahkamah Syariah di Malaysia.

Perbincangan umumnya menjurus kepada persoalan bidangkuasa Mahkamah Syariah (Farid Sufian, 2012: 85-113) dan pertindihan dengan Mahkamah Sivil (Arik Sanusi, 2012), jenayah Syariah, prosedur jenayah Syariah (Ahmad Azam, 2011: 1-18), keterangan dan pembuktian (Mohd Nasran, 1994: 71-88), kepegawaian, lantikan Hakim Syarie termasuk hakim wanita, penghakiman dan sebagainya. Kajian-kajian umum ini wajar dibuat secara teratur dan teliti agar ianya menampakkan kualiti proses penyelidikan.

\section{Perbincangan Fiqh berkenaan dengan Kehakiman dalam Islam}

Konsep dan teori Kehakiman Islam telah banyak dibincangkan dari perspektif Fiqh. Walau bagaimanapun, perbincangan adalah bersifat umum 
dalam kerangka teoritikal memahami kehakiman Islam. Perbincangan lebih mudah dilihat berdasarkan kepada kitab-kitab fiqh mazhab antaranya kitab al-Umm karangan al-Imām Shāfi'ī menghuraikan pada bab al- 'Aqụ̂̀yah (alShāfi' $\overline{1}, 2001$ : 487). Perbincangan adalah bersifat umum bagi menghuraikan masalah kehakiman dan juga adab-adab seorang hakim, perkara ini juga dihuraikan oleh al-Sharbīnī dalam kitab Mughnī al-Muḥtāj (al-Sharbīnī, 1997). Bagi mazhab lain antaranya, Ibn Qudāmah (Ibn Qudāmah, 2004: 2507) dan al-Bahūtī (al-Bahūtī, 2006: 772) dari mazhab Ḥanbalī, manakala al-Qurāfī dan Ibn Farhūn dari mazhab Mālikī juga menghuraikan berkenaan dengan kerangka kehakiman Islam yang mana kesemuanya meletakkan asas yang sama, iaitu kehakiman adalah berpaksikan kepada al-Quran dan hadis Nabi SAW (al-Qurāfī, 1994; Ibn Farḥūn, 2003).

Terdapat juga perbincangan mengenai kehakiman Islam yang disusun oleh ulama mutaakhirin dengan menghuraikan secara umum berkenaan dengan teori kehakiman termasuk adab-adab hakim (Mușțafā al-Khin, 2011) (Muḥammad al-Zuhaylī, 2011). Perbincangan yang dibawa oleh Wahbah al-Zuhaylī lebih menjurus kepada perbincangan kehakiman daripada sudut pandangan empat mazhab termasuklah syarat perlantikan hakim yang terperinci (Wahbah al-Zuhaylī, 1985: 477-509). Terdapat juga perbincangan berkenaan dengan kehakiman Islam dan juga keterangan-keterangan dalam perbuktian ('Abd al-Karīm Zaydān, 2011) (al-Harīīi, 1999).

\section{Kajian Lepas berkenaan dengan Kehakiman Islam dan Mahkamah Syariah di Malaysia}

Kajian berkenaan dengan kehakiman Islam dan Mahkamah Syariah sudah menjadi satu penyelidikan yang aktif di Malaysia. Antara kajian yang dilakukan tentang kehakiman Islam (Abdul Monir, 2009: 1-20) \& (Zaini Nasohah, 2004: 1-23) adalah kajian berkenaan dengan kerangka asas institusi kehakiman Islam daripada sudut bidangkuasa kehakiman, pengkhususan kehakiman dan keperluan kehakiman Islam. Perkara ini dihuraikan lebih mendalam oleh Arik Sanusi yang membawa perbincangan kepada kehakiman Islam di Malaysia. Kajian membincangkan berkenaan Sistem Kehakiman Sivil dan Syariah di Malaysia. Perbincangan juga lebih menumpukan kepada pentadbiran dan konflik di antara Mahkamah Syariah dan Mahkamah Sivil. Isu penghakiman juga ada diterangkan tetapi lebih menumpukan kepada perbincangan bidangkuasa antara Mahkamah Sivil dan Syariah dan tidak menyentuh kepada penghakiman dalam kes Mahkamah Syariah (Arik Sanusi, 2012).

Malaysia juga mempunyai sejarah yang panjang tentang pembentukan Mahkamah Syariah sehinggalah terbentuk Mahkamah Syariah pada masa kini 
(Ramizah, 2011). Abdul Monir Yaacob menambah bahawa Mahkamah Syariah perlulah disusun semula dan diberi kuasa yang lebih besar dan menyeluruh (Abdul Monir, 2009). Perkembangan Undang-Undang Islam di Malaysia adalah sangat terbatas, iaitu undang-undang diri dan hanya dalam ruang lingkup negeri sahaja (Shazalyna, 2012). Ruang lingkup ini pula agak terbatas daripada sudut pelaksanaan undang-undang jenayah yang menyukarkan pelaksanaan hudud kerana batasan undang-undang (Ashgar Ali, 2012).

Farid Sufian menerangkan berkenaan dengan perundangan Islam di Malaysia termasuklah daripada sudut kelayakan untuk mendapat jawatan kehakiman "qualification for appointment as a judge" yang mana perlu memenuhi kelayakan yang ditetapkan oleh Jabatan Perkhidmatan Awam (JPA), iaitu Sarjana Muda dalam bidang Syariah atau LL.B dan mempunyai Diploma Pentadbiran Kehakiman Islam (DAIJ). Daripada sudut bidangkuasa, penulis menyatakan bahawa undang-undang di Malaysia memberi kuasa kepada negeri untuk membuat Mahkamah Syariah bagi orang Islam di negeri tersebut (Farid Sufian, 2012). Lantikan Peguam Syarie di Malaysia adalah merujuk kepada kaedah-kaedah Peguam Syarie negeri-negeri yang mana lantikan adalah di bawah bidangkuasa negeri untuk beramal di Mahkamah Syariah (Ibnor Azli, 2013).

Terdapat juga isu-isu bidangkuasa Mahkamah Syariah yang dikaitkan berkenaan dengan isu-isu yang melibatkan orang bukan Islam (Farid Sufian, 2008) antaranya isu hadānah. Walaupun Mahkamah Syariah di bawah bidangkuasa negeri, pihak Jabatan Kehakiman Islam Malaysia (JKSM) memainkan peranan penting dalam pentadbiran daripada sudut lantikan hakim, Pendakwa Syarie dan pegawai Sulh. Ianya bukanlah sebagai menafikan kuasa Sultan tetapi sebagai memudahkan urusan pentadbiran Islam di Malaysia "the establishment of the JKSM is not meant to take away the power of each sultan or king as the head of religion, but it is a simple administrative device to streamline the administration and bring uniformity of Islamic law"(Ramizah, 2011: 242-252).

Antara tulisan yang membincangkan berkaitan dengan Mahkamah Syariah di Malaysia adalah tulisan (Raihanah Azahari, 2005; Zaini Nasohah, 2007) dan sebagainya. Terdapat banyak kajian berkenaan dengan Mahkamah Syariah yang dikaji daripada pelbagai skop dan perbincangan termasuk daripada sudut keterangan, tatacara dan sebagainya. Raihanah Abdullah telah mengkaji berkenaan Mahkamah Syariah daripada sudut penangguhan kes di Mahkamah Syariah. Penulis telah merujuk kes Aida Melly Tan Mutalib ${ }^{1}$ untuk dijadikan kes rujukan utama tentang isu ini. Kes-kes lain juga ada dirujuk tetapi tidak

$1 \quad$ Aida Melly Tan Mutalib [2008] 1 ShLR 85. 
membincangkan secara terperinci tentang isu penghakiman yang dibuat oleh hakim bicara atau hakim rayuan.

Walau bagaimanapun, Raihanah Abdullah (2009) menyatakan bahawa JKSM perlu memainkan peranan untuk mengembalikan imej Kehakiman Syariah yang telah tercalar. Perkara ini dinyatakan "various positive steps are taken by authorities to upgrade the administration quality in Shariah Court." Terdapat juga kajian berkenaan Mahkamah Syariah daripada sudut pelaksanaan saman penghutang penghakiman yang mana dibuat kesimpulan perintah penghakiman adalah kebanyakan gagal dan ingkar dipatuhi sehinggakan saman penghutang penghakiman dilaksanakan (Zaini Nasohah \& Suwaid Tapah, 2001: 43-52). Terdapat juga isu pelaksanaan perintah nafkah yang gagal dipatuhi ini daripada perspektif Peguam Syarie di Mahkamah Syariah Selangor (Zaini Nasohah, 2009).

Berkenaan dengan Mahkamah Syariah, terdapat kajian berkenaan dengan keterangan daripada sudut pemakaian Iqrar yang digunakan di Mahkamah Syariah dan juga perbandingan dengan Mahkamah Sivil (Mohd Nasran, 1994: 71-88). Ruzman Md. Noor (2008: 143-167) juga telah mengkaji berkenaan dengan Mahkamah Syariah tetapi perbincangan diskopkan kepada konteks keterangan dengan menganalisis daripada perspektif mazhab Shāfi '`̃. Penulis membawa method perbandingan (comparative method) dalam penulisannya, iaitu membandingkan undang-undang berdasarkan Enakmen Keterangan Mahkamah Syariah Melaka 2002 untuk dibandingkan dengan konteks mazhab Shāfi' $\overline{1}$ dengan menggunakan kitab fiqh muktabar. Hasil dapatan penulis menunjukkan bahawa pandangan dalam mazhab Shāfi'ī mendominasi peruntukan dalam enakmen ini.

\section{Kajian Lepas berkenaan dengan Penghakiman Mahkamah Syariah di Malaysia}

Terdapat kajian berkenaan dengan Mahkamah Syariah daripada sudut alasan penghakiman. Shuhairimi \& Saidi Md Noor (2011) telah membuat kajian terhadap alasan penghakiman bagi kes jenayah Syariah. Hasil kajian menunjukkan terdapat Hakim Syarie yang tidak mencatat dengan sempurna sesuatu rekod perbicaraan dan tidak merujuk undang-undang dalam mensabitkan tertuduh. Perkara ini tidak dapat dipastikan sama ada dilakukan dengan sengaja atau tidak. Takat hukuman juga dibincangkan yang mana julat hukuman bagi sesuatu kesalahan sangat besar bagi kes-kes yang disabitkan kerana ketiadaan standard hukuman minimum. 
Ainul Bashirah (2012: 65-88) dalam kajiannya telah merujuk beberapa kes yang melihat kepada takat hukuman dan penghakiman yang diputuskan oleh Hakim Syarie. Kesimpulan yang dibuat adalah hukuman yang sedia ada seperti kurang memberi pengajaran kepada masyarakat agar menghindari perbuatan khalwat dan perbuatan tidak sopan dalam jenayah Syariah di Malaysia. Berkenaan dengan takat hukuman Jasri Jamal \& Siti Nor Farahiyah (2012: 179-200) dalam kajian yang dilakukan mendapati bahawa dalam kes-kes yang diputuskan dan dilaporkan ke dalam Jurnal Hukum hampir kebanyakannya adalah membincangkan berkenaan dengan takat hukuman yang telah diberikan oleh Mahkamah Rendah Syariah.

Dari tahun 2007 kes yang telah direkod menunjukkan bahawa keskes pemenjaraan diakas atau diketepikan apabila sesuatu rayuan dibuat di mahkamah yang lebih tinggi. Dalam alasan penghakiman yang dibuat terdapat banyak isu yang dikemukakan sewaktu rayuan dilakukan. Walau bagaimanapun, kebanyakan kes yang melibatkan rayuan takat hukuman menjelaskan bahawa Hakim Syarie di peringkat mahkamah bicara gagal menimbangkan takat hukuman kepada tertuduh-tertuduh. Persoalan yang ditimbulkan dalam kajian adalah bagaimana penilaian Hakim Syarie terhadap hukuman dan apakah faktor-faktor yang dipertimbangkan oleh Hakim Syarie dalam menjatuhkan hukuman, mengurangkan hukuman atau meminda hukuman yang telah diputuskan.

Siti Zubaidah Ismail (2008: 83-92) membincangkan penulisan penghakiman bagi kes jenayah Syariah yang mana terdapat dua bentuk penulisan penghakiman. Pertama adalah penulisan penghakiman apabila tertuduh mengaku bersalah dan kedua adalah penulisan penghakiman apabila proses perbicaraan kerana tertuduh tidak mengaku bersalah. Kedua-dua bentuk ini adalah berbeza. Walau bagaimanapun, perkara yang penting bagi kedua-dua penulisan penghakiman ini adalah rekod-rekod perbicaraan yang dilakukan di hadapan Hakim Syarie. Penulis tidak mengemukakan secara terperinci berkenaan dengan kes-kes dari sudut keterangan dan rekod-rekod dalam penulisan penghakiman termasuklah perbincangan penulisan penghakiman kes jenayah dari aspek fiqh. Penulis membawa kajian kepada satu senario di peringkat Mahkamah Syariah di Malaysia adalah bahawa ketiadaan teks atau alasan penghakiman yang berwibawa adalah kerana kes-kes jenayah tidak merumitkan.

Dalam hal ini, perincian penulisan alasan penghakiman di Mahkamah Syariah adalah amat signifikan dalam membuktikan kelicinan pentadbiran dan secara tidak langsung keadilan tertegak di institusi Mahkamah Syariah Malaysia. Raihanah Abdullah (2008: 69-82) telah membincangkan berkenaan penulisan penghakiman dari aspek kekeluargaan di Mahkamah Syariah. 
Dalam kajian yang dilakukan, penulis hanya memfokuskan kepada teks penghakiman kes cerai talak tiga. Perbincangan penulis walaupun hanya satu kes, ianya telah mengeluarkan banyak isu yang dibincangkan daripada sudut keterangan, pensabitan talak berdasarkan pendapat fuqaha' dan kes-kes yang dirujuk daripada Jurnal Hukum.

Penulis menyatakan, terdapat kecenderungan mahkamah di peringkat perbicaraan, kes ini mensabitkan tiga talak, namun berbeza dengan perbicaraan di peringkat jawatankuasa ulang bicara yang sangat berhati-hati dalam keputusan pensabitan talak tiga. Dalam hal ini, alasan penghakiman yang jelas adalah amat penting dan hakim perlu mengemukakan alasan yang kukuh dalam menjatuhkan hukuman di samping pihak-pihak yang terbabit memperolehi keadilan. Mohd Norhusairi (2014) dalam kajiannya ada menyentuh berkenaan dengan penghakiman kes-kes harta sepencarian, penulis ada mengemukakan kepentingan Alasan Penghakiman untuk mengkaji cara dan asas pertimbangan yang telah digunakan oleh Hakim Syarie dalam menilai tuntutan harta sepencarian.

Daud Muhammad (2009: 149-161) dalam penulisannya menyatakan tentang cara penulisan teks penghakiman di Mahkamah Syariah daripada sudut kaedah dan pendekatan hendaklah mengikut Hukum Syarak. Walau bagaimanapun, penulisan ini memberi dapatan bahawa penghakiman di Mahkamah Syariah perlu mengikut kaedah dan pendekatan menepati kehendak Hukum Syarak berdasarkan penelitian kenyataan pihak-pihak, fakta kes, rujukan nas alQuran dan Hadis serta pendapat fuqaha' yang muktabar. Perbincangan dalam penulisan ini tidak mendedahkan secara terperinci berkenaan dengan penulisan penghakiman yang diaplikasikan di peringkat Mahkamah Syariah di Malaysia. Walaubagaimanapun, penulis memberikan makluman yang penting, yang mana kunci kepada penghakiman yang kukuh adalah mengikut kehendak Hukum Syarak dan undang-undang yang berkuatkuasa.

GhazaliAbd. Rahman (2005: 189-216) dalam penulisannya membincangkan berkenaan dengan proses penghakiman di Mahkamah Syariah. Penulis menyatakan Hakim Syarie dalam menjalankan sesuatu keputusan untuk meneruskan perbicaraan adalah dengan melihat kepada penentuan bidangkuasa. Adab dan garis panduan Hakim Syarie sebelum membuat penghakiman atau menjatuhkan hukuman perlu diberi perhatian agar hukuman yang dibuat bukan berdasarkan kepada publisiti, kemarahan, kekaburan dan sebagainya. Perkara penting yang dinyatakan oleh penulis adalah berkenaan Hakim-Hakim Syarie perlu menjadi orang yang profesional, berilmu dan adil di dalam keputusan yang dibuat. 
Faiza Tamby Chik (2009: 137-148) dalam penulisannya menghuraikan berkenaan dengan prinsip-prinsip dalam membuat penghakiman di peringkat Mahkamah Sivil yang mana semua Hakim Mahkamah Sivil hendaklah mengikut prinsip-prinsip yang telah digariskan dalam menetapkan sesuatu hukuman dan penghakiman. Prinsip yang digariskan adalah hakim perlu mendengar keterangan pihak-pihak dan tidak boleh membuat keputusan secara menduga atau meneka. Dalam Mahkamah Sivil perkara yang sangat ditekankan adalah doktrin duluan mengikat (binding precedent), sekiranya hakim tidak mengikut prinsip ini maka hakim tersebut telah mengabaikan tugasnya. Pihak mahkamah juga perlu mengikut prosedur dan undang-undang yang tepat dalam menjalankan sesuatu penghakiman di dalam Mahkamah Sivil. Faiza Tamby Chik (2008: 33-43) menambah lagi di dalam penulisannya yang lain untuk dikaitkan dengan penghakiman di peringkat Mahkamah Syariah adalah hakim rayuan perlu memberi pertimbangan dalam membuat keputusan dengan merujuk kepada kandungan teks penghakiman di peringkat mahkamah bicara dan rujukan ke atas kes-kes terdahulu serta sumber Hukum Syarak dalam menjalankan penghakiman di Mahkamah Syariah.

Walau bagaimanapun, Suwaid Tapah (2008: 45-51) mengatakan dalam kajiannya bahawa Mahkamah Syariah tidak terikat untuk melaksanakan prinsip duluan mengikat (binding precedent), hal ini kerana ianya sudah meninggalkan dua sumber asas iaitu al-Quran dan al-Sunnah. Adapun rujukan yang dibuat oleh hakim-hakim dalam kebanyakan teks penghakiman dalam membuat keputusan adalah merujuk kes-kes yang berkaitan sebagai rujukan termasuk kes-kes Mahkamah Sivil untuk melihat berkaitan tafsiran bidangkuasa perundangan. Suwaid Tapah menjelaskan bahawa penekanan terhadap sumber rujukan Hukum Syarak adalah menjadi identiti untuk Hakim-Hakim Syarie membuat penghakiman di Mahkamah Syariah. Penulisan penghakiman juga perlu menyeluruh termasuk penekanan tentang aspek keterangan daripada sudut aspek fakta, keterangan lisan, dokumen syahädah dan qarinah.

\section{KESIMPULAN}

Maka melihat daripada sorotan kajian lepas menunjukkan bahawa kajian berkenaan kehakiman di Mahkamah Syariah adalah penyelidikan yang aktif. Walaubagaimanapun, kajian berkenaan dengan penghakiman masih lagi kurang terhadap metodologi Hakim Syarie berhukum, pemakaian prinsipprinsip penghakiman yang tepat dan Syarie, keterangan, rujukan, rekod catatan perbicaraan, pertimbangan, dan keputusan hakim. Seterusnya, satu kajian terperinci dan mendalam perlu dibuat untuk mengkaji metodologi Hakim-Hakim Syarie membuat satu pertimbangan keputusan dalam kes-kes 
di Mahkamah Syariah yang melibatkan kes jenayah dan kes kekeluargaan. Kajian ini perlu dilakukan untuk menambah nilai-nilai ilmiah daripada kajiankajian lepas dan secara tidak langsung ianya mampu memberi nilai tambah kepada Hakim-Hakim Syarie agar dapat membuat satu penghakiman yang betul, tepat, berkesan dan wajar berdasarkan prinsip keadilan yang Syarie.

\section{RUJUKAN}

'Abd al-Karīm Zaydān (2011). Niz̄ām al-Qaḍā' fì al-Sharī'ah al-Islāmiyyah. Beirūt: Mu'assasah al-Risālah Nāshirūn.

Abdul Monir Yaacob (2009). "Perlaksanaan Perundangan Islam di Malaysia: Satu Penilaian." Jurnal Fiqh, vol. 6, 1-20.

Ahmad 'Azam Mohd Shariff (2011). "Prosedur Pendakwaan Jenayah Syariah: Analisis ke Atas Peruntukan Undang-Undang di bawah Akta Prosedur Jenayah Syariah (Wilayah-wilayah Persekutuan) 1997 dan Akta Keterangan Mahkamah Syariah (Wilayah-wilayah Persekutuan) 1997." Jurnal Undang-Undang Malaysia, vol. 15, 1-18.

Ainul Bashirah Ismail, Zuliza Mohd Kusrin \& Mat Noor Mat Zain (2012). "Kesalahan Khalwat dan Perbuatan Tidak Sopan dan Hukumannya Menurut Islam.” Jurnal Hadhari, vol. 4 (2), 65-88.

Akademi Pengajian Islam (t.t.). Buku Panduan Penulisan Tesis/Disertasi Ijazah Tinggi Akademi Pengajian Islam. Kuala Lumpur: Akademi Pengajian Islam Universiti Malaya.

al-Bahūtī, Mansūr bin Yūnus bin Șalāḥ al-Dīn (2006). al-Minah al-Shāfiyāt bi Sharh Mufradāt al-Imām Aḥmad, vol. 2. Riyāḍ: Dār Kunūz Ishbīliyā li al-Nashr wa al-Tawzī'.

al-Harīīī, Muhammad (1999). al-Qawā'id wa al-Dawābiṭ al-Fiqhīyyah li Niz̄ām al-Qaụa'fí al-Islām. Oman: Dār 'Imār li al-Nashr.

al-Qurāfī, Shihāb al-Dīn Aḥmad bin Idrīs (1994). al-Dhakhīrah, vol. 10. Beirūt: Dār al-Gharb al-Islāmī.

al-Sharbīnī, Shams al-Dīn Muḥammad bin al-Khațīb (1997). Mughnī al-Muhtāj Ilā Ma 'rifah Ma 'ānì Alfāz al-Minhāj, vol. 4. Beirut: Dār al-Ma'rifah.

Arik Sanusi Yeop Johari (2012). "Pembaharuan Sistem Kehakiman Syariah dan Sivil di Malaysia.” Tesis Kedoktoran, Universiti Malaya.

Ashgar Ali Ali Mohamed (2012). "Implementation of Hudud (or limits ordained by Allah for serious crimes) in Malaysia." International Journal of Humanities and Social Science, vol. 2 (3), 237-246. 
Daud Muhammad (2009). "Penulisan Teks Penghakiman di Mahkamah Syariah: Kaedah dan Pendekatan.” Jurnal Hukum, vol. 28 (2), 149-161.

Faiza Tamby Chik (2008). "Perbandingan Kaedah Penulisan Teks Penghakiman", dalam Penulisan Teks Penghakiman di Mahkamah Syariah, ed. Ruzman Md. Noor. Kuala Lumpur: Penerbit Universiti Malaya, 33-43.

Faiza Tamby Chik (2009). "Penulisan Teks Penghakiman di Mahkamah Sivil: Kaedah dan Pendekatan.” Jurnal Hukum, vol. 28 (2), 137-148.

Farid Sufian Shuaib (2008). "Strengthening Administrative Institutions of Islamic Law in Malaysia: An Overview." Shariah Journal, vol. 16, Special Edition, 443-464.

Farid Sufian Shuib (2012). "The Islamic Legal System in Malaysia.” Pacific Rim Law \& Policy Journal, vol. 21 (1), 85-113.

Ghazali Abd. Rahman (2005). "Proses Penghakiman dan Menjatuhkan Keputusan di Mahkamah Syariah: Satu Penilaian.” Jurnal Hukum, vol. xix (2), 189-216.

Ibn Farhūn, al-Imām al-'Allāmah Burhān al-Dīn Ab̄̄ al-Wafa’ Ibrāhim Ibn alImām Shams al-Dīn Abī 'Abd Allah Muhammad (2003). Tabșirah alHukkām fì Ușūl al- 'Aqụiyyah wa Manāhij al-Aḥkām, vol. 1. Riyāḍ: Dār 'Ālam al-Kutub.

Ibn Qudāmah al-Maqdis̄̄ (2004). al-Mughnī. Lubnan: Bayt al-Afkār alDawliyyah.

Ibnor Azli Ibrahim, Ahmad Muhammad Husni \& Ismail Rashed Abood Almashaqbeh (2013). "Sharia Legal System and Its Implementation in Malaysia." International Journal of West Asian Studies, vol. 5 (1), 93104.

Jasri Jamal \& Siti Nor Farahiyah Zakariah (2012). "Kes-Kes Jenayah Syariah Yang Dilaporkan dalam Jurnal Hukum JKSM dari Tahun 2007-2011: Satu Analisis Ringkas.” Jurnal Hukum, vol. 35 (2), 179-200.

Mohd Nasran Mohamad (1994). "Islamic Law of Evidence in Confession (Iqrar): Definitions and Conditions." Jurnal Islamiyyat, vol. 15, 71-88.

Mohd Norhusairi Mat Hussin (2014), “Konsep Sumbangan dalam Penentuan Pembahagian Harta Sepencarian di Mahkamah Syariah Malaysia: Perspektif Sosio-Perundangan.” Tesis Kedoktoran, Jabatan Syariah dan Undang-Undang, Akademi Pengajian Islam, Universiti Malaya).

Muhammad al-Zuhaylī (2011). al-Mu'tamad fì al-Fiqh al-Shāfi's, vol. 5. Damsyiq: Dār al-Qalam. 
Muhammad bin Idrīs al-Shāfi‘̄i (2001). al-Umm, vol. 7. al-Manșūrah: Dār alWafā li al-Ṭabā'ah wa al-Nashr wa al-Tawzī'.

Mușțafā al-Khin, Mușțafā al-Bughā \& 'Alī Al-Sharbij̄̄ (2011). al-Fiqh alManhajī 'alā Madhhab al-Imām al-Shāfi '`, vol. 3. Damsyiq: Dār alQalam.

Raihanah Abdullah (2008). "Penulisan Teks Penghakiman Kes-Kes kekeluargaan di Mahkamah Syariah", dalam Penulisan Teks Penghakiman di Mahkamah Syariah, ed. Ruzman Md. Noor. Kuala Lumpur: Penerbit Universiti Malaya, 69-82.

Raihanah Abdullah (2009), "Penangguhan Kes di Mahkamah Syariah: Cabaran dan Penyelesaian.” Jurnal Syariah, vol. 17 (1), 15.

Raihanah Azahari (2005). "Sulh dalam Perundangan Islam: Kajian di Jabatan Kehakiman Syariah Selangor Darul Ehsan.” Tesis Kedoktoran, Universiti Malaya).

Ramizah Wan Muhammad (2011). "The Administration of Syariah Court in Malaysia 1957-2009." Journal of Islamic Law and Culture, vol. 13 (23), 242-252.

Ruzman Md. Noor (2008). "Kesaksian dalam Konteks Undang-Undang Keterangan Mahkamah Syariah di Malaysia: Analisis dari Perspektif Mazhab Shafi'i.” Jurnal Fiqh, vol. 5, 143-167.

Sabitha Marican (2005). Kaedah Penyelidikan Sains Sosial. Selangor: Pearson Malaysia Sdn. Bhd.

Sharaf al-Dīn, 'Īsā bin 'Uthmān bin 'Īsā bin Ghāzī al-Ghuzz̄i Abū Rūḥ (1996). Adab al-Qaḍa' '. Riyāḍ: Maktabah Nazār Musțafā al-Bāz.

Shazalyna Mohammad (2012). “The Paradox of Women's Rights: Malaysia's Struggle Towards Legal and Religious Pluralism.” Disertasi Sarjana, Department of the Faculty of Law, University of Toronto.

Shuharaimi Abdullah \& Saidi Md Noor (2011). Alasan Penghakiman Mahkamah Syariah. Kangar: Penerbit Universiti Malaysia Perlis.

Siti Zubaidah Ismail (2008). "Penulisan Teks Penghakiman Kes-Kes Jenayah di Mahkamah Syariah", dalam Penulisan Teks Penghakiman di Mahkamah Syariah, ed. Ruzman Md. Noor. Kuala Lumpur: Penerbit Universiti Malaya, 83-92.

Suwaid Tapah (2008). "Penulisan Teks Penghakiman Kes-Kes Mal di Mahkamah Syariah", dalam Penulisan Teks Penghakiman di Mahkamah Syariah, ed. Ruzman Md. Noor. Kuala Lumpur: Penerbit Universiti Malaya, 45-51. 
Syed Agil Barakbah (2000) "Hakim dan Penghakiman", dalam Al-Ahkam, ed. Ahmad Ibrahim et al., vol. 5. Kuala Lumpur: Dewan Bahasa dan Pustaka.

Wahbah al-Zuhaylī (1985). al-Fiqh al-Islāmī wa Adillatuh, vol. 6. Damsyiq: Dār al-Fikr li al-Ṭabā'ah wa al-Nashr wa al-Tawzī'.

Zaini Nasohah \& Suwaid Tapah (2001). “Analisis Pelaksanaan Prosiding Saman Penghutang Penghakiman dalam Penguatkuasaan Perintah Pembayaran Nafkah: Kajian Kes Mahkamah Syariah Negeri Selangor.” Jurnal Undang-Undang Malaysia, vol. 15, 43-52.

Zaini Nasohah (2004). "Institusi Kehakiman Islam" dalam al-Syariah Kehakiman Islam, ed. Siti Zalikhah Haji Md. Nor et al., vol. 2. Kuala Lumpur: Dewan Bahasa dan Pustaka, 1-23.

Zaini Nasohah (2007). "Penguatkuasaan dan Pelaksanaan Perintah Nafkah: Kajian di Mahkamah Syariah Selangor (1999-2004).” Tesis Kedoktoran, Universiti Malaya).

Zaini Nasohah (2009). "Cabaran Penguatkuasaan dan Pelaksanaan Perintah Nafkah di Mahkamah Syariah Negeri Selangor dari Perspektif Peguam Syar'ie." Jurnal Undang-Undang, vol. 13, 115-128.

\section{Senarai Kes}

Abdul Rahman bin Shafie lwn. Husna binti Senawi dan seorang lagi [1998] JH jilid xii, (II) 231.

Abdul Hanif lwn. Rabiah [1996] 11 JH 47

Aida Melly Tan Mutalib [2008] 1 ShLR 85. 